\title{
Role of Fecal Calprotectin in Diagnosis and Follow up of Hepatic Encephalopathy
}

\author{
Inas Elkhedr Mohamed ${ }^{1}$, Fatma Ahmed Ali-Eldin ${ }^{2, *}$ \\ ${ }^{1}$ Internal Medicine Department, Faculty of Medicine, Ain Shams University, Cairo, Egypt \\ ${ }^{2}$ Tropical Medicine Department, Faculty of Medicine, Ain Shams University, Cairo, Egypt \\ Email address: \\ Inas-elkhedr@yahoo.com (I. E. Mohamed), fatmaalieldin@yahoo.com (F. A. Ali-Eldin) \\ ${ }^{*}$ Corresponding author
}

\section{To cite this article:}

Inas Elkhedr Mohamed, Fatma Ahmed Ali-Eldin. Role of Fecal Calprotectin in Diagnosis and Follow up of Hepatic Encephalopathy. International Journal of Clinical and Experimental Medical Sciences. Vol. 3, No. 6, 2017, pp. 82-86. doi: 10.11648/j.ijcems.20170306.14

Received: February 26, 2017; Accepted: March 24, 2017; Published: December 5, 2017

\begin{abstract}
Fecal calprotectin is considered a valid marker of intestinal inflammation and its high level in patients with HE may be explained by small intestinal bacterial overgrowth. This study aimed to assess the role of fecal calprotectin in diagnosis and follow up of patients with hepatic encephalopathy. Fifteen patients with uncomplicated liver cirrhosis, 30 patients with liver cirrhosis complicated by hepatic encephalopathy (HE) and 15 healthy subjects were enrolled. All participants were subjected to: clinical examination, laboratory investigations (CBC, liver function tests, kidney functions, $\mathrm{HBs} \mathrm{Ag}$ and $\mathrm{HCV}$ Antibody), fecal calprotectin concentration, abdominal ultrasound. Severity of HE was assessed according to West-Haven criteria. Patients with HE was managed using metronidazole and rifaximin and fecal calprotectin concentrations were reassessed. The level of fecal calprotectin is significantly higher in patients with Child-Pugh class B $(116 \pm 12 \mathrm{mg} / \mathrm{kg})$ versus that in class A $(66 \pm 15 \mathrm{mg} / \mathrm{kg})(\mathrm{p}<0.01)$. FC concentrations showed the lowest value in the cirrhotic group $(66+15 \mathrm{mg} / \mathrm{kg})$ followed by low grade $\mathrm{HE}(195+12 \mathrm{mg} / \mathrm{kg})$ and the highest value in the high grade $\mathrm{HE}$ group $(489+23 \mathrm{mg} / \mathrm{kg})(\mathrm{p}<0.01)$. A significant decrease in FC concentrations occurred in HE group after receiving treatment, reaching a level of $273+42.68 \mathrm{mg} / \mathrm{kg}$ versus $364+83.12 \mathrm{mg} / \mathrm{kg}$ before rifaximin. In conclusion: Fecal calprotectin can be used in diagnosis of HE. Significant high levels of fecal calprotectin in high grade HE patients and its reduction following effective treatment could consider fecal calprotectin as a follow up marker in association with clinical signs in patients with HE.
\end{abstract}

Keywords: Fecal Calprotectin, Liver Cirrhosis, Hepatic Encephalopathy

\section{Introduction}

Hepatic encephalopathy (HE) is a complex neuropsychiatric syndrome associated with acute, subacute and chronic liver failure, involving increased neural inhibition by activation of the GABA/benzodiazepine inhibitory neurotransmitter system [1]. Diagnosis of HE continues to be a clinical problem as patients may present with mild cognitive impairment. It is important to diagnose HE early because adequate treatment of the condition reduces morbidity and mortality [2].

Calprotectin is a calcium and zinc-binding protein, representing more than $60 \%$ of the cytosolic proteins in neutrophils. The presence of calprotectin in feces quantitatively relates to neutrophil migration into the gastrointestinal (GI) tract [2]. Therefore, it is considered a valid marker of intestinal inflammation because it is released during cell activation and death as the GI tract of cirrhotic patients shows various alterations of its mucosal barrier including infiltrates of neutrophils, calprotectin might be a promising diagnostic parameter to diagnose the onset and course of HE. The high level of fecal calprotectin (FC) in patients with $\mathrm{HE}$ may be explained by small intestinal bacterial overgrowth. A significant association emerged between elevated FC and $\mathrm{HE}$ grading as measured by WestHaven criteria [3]. This study aimed to assess the role of fecal calprotectin in diagnosis and follow up of HE in chronic HCV patients. 


\section{Patients and Methods}

45 patients with liver cirrhosis were enrolled from Ain Shams University hospital during the period from September 2015 to March 2016. Patients were divided into two groups: 15 patients with uncomplicated liver cirrhosis and 30 patients with liver cirrhosis complicated by hepatic encephalopathy. They received metronidazole $250 \mathrm{mg} / 6$ hours and rifaximin 400mg 3 times daily [4]. A third group included 15 healthy non cirrhotic subjects as a control group.

An informed written consent was obtained from each participant or responsible family members. The study protocol was consistent with the ethical guidelines of Helsinki.

Patients with inflammatory bowel disease, coeliac disease, colorectal carcinoma, active GI bleeding, certain drugs (e.g. non-steroidal anti-inflammatory drugs, anticoagulants, antibiotic therapy, proton pump inhibitors), food allergy and ongoing alcohol abuse were excluded from the study. Also, all patients with diarrhea were excluded from this study as GI infections may cause elevated fecal calprotectin.

All participants were subjected to: clinical examination, laboratory investigations $(\mathrm{CBC}$, liver profile, kidney functions, $\mathrm{HBs} \mathrm{Ag}$ and $\mathrm{HCV} \mathrm{Ab}$ ), abdominal ultrasound and fecal calprotectin concentration measurement before and after treatment of HE.

FC was done by enzyme linked immunosorbent assay (ELISA) (Calprest, Dynex Elisa Eurospital, Trieste, Italy). Samples were collected in disposable plastic containers and stored within 6 hours at $-20^{\circ} \mathrm{C}$ until analysis. Results are expressed in $\mathrm{mg}$ of calprotectin per kilogram of wet feces. The median value in healthy adults is about $25 \mathrm{mg} / \mathrm{kg}$, samples giving values above $50 \mathrm{mg} / \mathrm{kg}$ are regarded as positive [5].

The diagnosis of liver cirrhosis was based on clinical, laboratory and radiological findings.
Severity of HE were assessed according to West-Haven criteria [6].

Statistical Methodology: Analysis of data was done by IBM computer using SPSS. Description of quantitative variables as mean, SD and range, description of qualitative variables as number and percentage, Chi-square test was used to compare qualitative variables between groups. Unpaired t-test was used to compare quantitative variables, in parametric data ( $\mathrm{SD}<50 \%$ mean). Mann Whitney Willcoxon test was used instead of unpaired t-test in nonparametric data ( $\mathrm{SD}>50 \%$ mean). One way analysis of variance (ANOVA) test was used to compare more than two groups as regard quantitative variable.

Spearman Correlation co-efficient test was used to rank variables versus each other positively or inversely. ROC Curve was used to find out the best cut off value, and validity of certain variable. $p$ value $>0.05$ insignificant, $p<0.05$ significant, and $\mathrm{p}<0.01$ highly significant.

\section{Results}

60 subjects included in the study. 15 non-complicated cirrhotics and 30 cirrhotic patients complicated with hepatic encephalopathy and 15 healthy control subjects.

Among uncomplicated cirrhotics, 12 patients were males $(80 \%)$ and 3 were females $(20 \%)$, their mean age was $51.6 \pm 8$ years. among HE patients, 15 were males $(50 \%)$ and 15 were females $(50 \%)$, their mean age was $52.5 \pm 4$ years. Among healthy control subjects, six were males $(40 \%)$ and nine were females $(60 \%)$, their mean age was $50.5 \pm 9$ years $(\mathrm{p}>0.05)$.

According to West-Haven criteria, $3 \mathrm{HE}$ patients (10\%) were grade 0,9 patients $(30 \%)$ were grade I, 8 patients (28.67\%) were grade II, 7 patients $(23.33 \%)$ were grade III and 3 patients $(10 \%)$ were grade IV.

Laboratory data of the studied patients were summarized in table 1.

Table 1. Laboratory data of the studied groups.

\begin{tabular}{llll}
\hline Test value & HE $\mathbf{n}=\mathbf{3 0}$ & Uncomplicated Cirrhosis $\mathbf{n}=\mathbf{1 5}$ & Healthy controls n=15 \\
\hline $\mathrm{HB}(\mathrm{gm} / \mathrm{dl})$ & $9.1 \pm 0.8$ & $9.9 \pm 2$ & $12.6 \pm 1$ \\
Platelets $\left(10^{3} / \mathrm{mm}^{3}\right)$ & $75+20$ & $100 \pm 20$ & $352 \pm 38$ \\
WBCs $\left(10^{3} / \mathrm{mm}^{3}\right)$ & $4.6 \pm 1.6$ & $4 \pm 1.3$ & $5.5 \pm 1$ \\
PT (Seconds) & $18.5+2$ & $15.2 \pm 1.6$ & $12.1 \pm 2$ \\
INR & $1.8 \pm 0.4$ & $1.4 \pm 0.6$ & $1 \pm 0.04$ \\
Bilirubin $(\mathrm{mg} / \mathrm{dl})$ & $2.9 \pm 0.3$ & $1.5 \pm 0.3$ & $0.85 \pm 0.2$ \\
ALT $(\mathrm{IU} / \mathrm{L})$ & $80 \pm 39$ & $49+22$ & $22.6 \pm 4$ \\
AST $(\mathrm{IU} / \mathrm{L})$ & $61 \pm 23$ & $53+20$ & $25 \pm 15$ \\
Albumin $(\mathrm{gm} / \mathrm{dl})$ & $2.2 \pm 0.3$ & $3.5 \pm 1.1$ & $3.9 \pm 1.2$ \\
Na ${ }^{+}(\mathrm{mmol} / \mathrm{L})$ & $126 \pm 2$ & $137 \pm 1.1$ & $135 \pm 1$ \\
$\mathrm{~K}^{+}(\mathrm{mmol} / \mathrm{L})$ & $3.6 \pm 0.4$ & $4 \pm 0.3$ & $4.1 \pm 0.4$ \\
RBS $(\mathrm{mg} / \mathrm{dl})$ & $135 \pm 75$ & $148 \pm 41$ & $114 \pm 7.7$ \\
Creatinine $(\mathrm{mg} / \mathrm{dl})$ & $1.15 \pm 0.6$ & $0.86 \pm 0.2$ & $0.83 \pm 0.2$ \\
BUN $(\mathrm{mg} / \mathrm{dl})$ & $27 \pm 11$ & $21.5 \pm 8$ & $15.1 \pm 3$ \\
\hline
\end{tabular}

Fecal calprotectin levels were significantly higher in uncomplicated cirrhotic patients and patients with $\mathrm{HE}$ in comparison to healthy control. Also, it was significantly higher in patients with hepatic encephalopathy in comparison to cirrhotics with significant reduction of FC levels after completion of treatment (table 2, figure 1). 
Table 2. The level of fecal calprotectin in the studied groups.

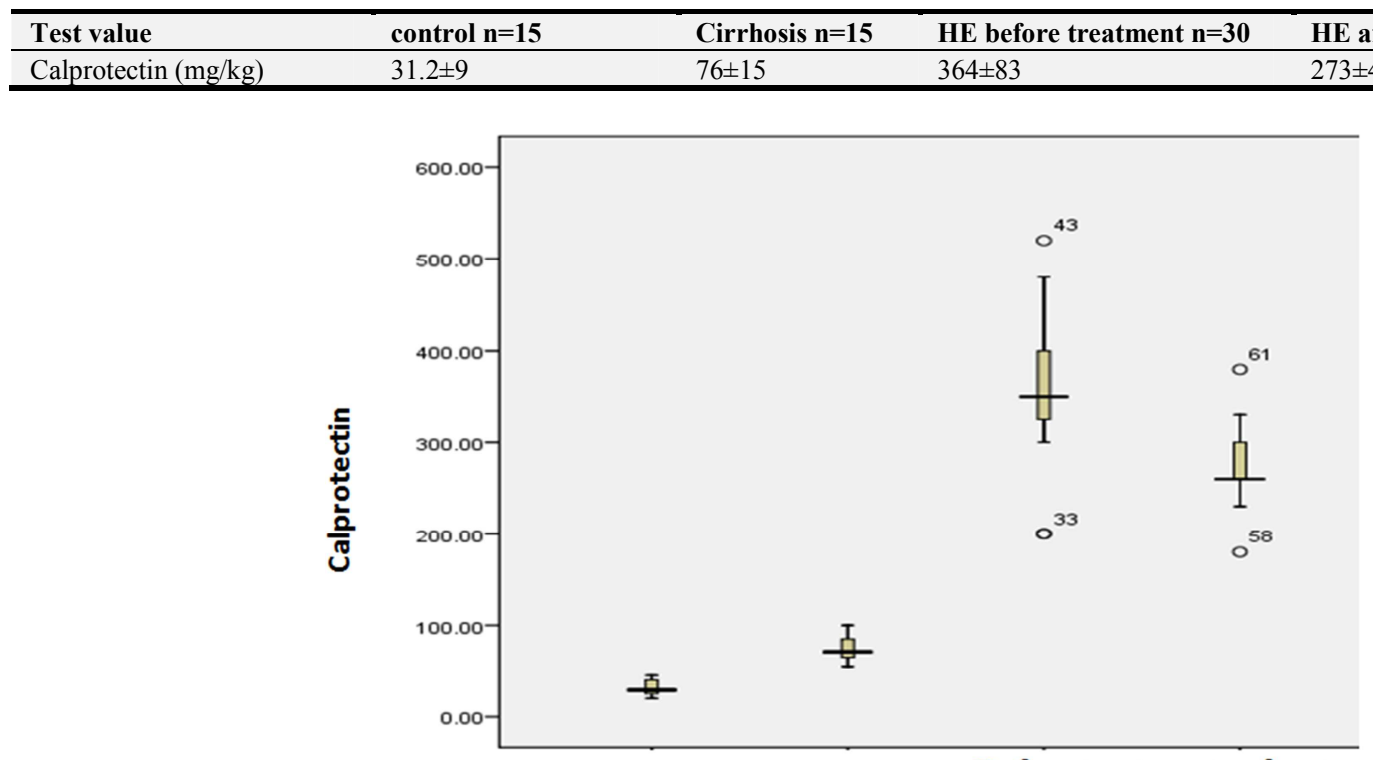

Before treatment after treatment

Figure 1. Fecal calprotectin levels in the different studied groups.

Among the uncomplicated cirrhotics, 12 patients were child A with FC concentration $66 \pm 15 \mathrm{mg} / \mathrm{kg}$ and 3 were child B with FC levels $116 \pm 12 \mathrm{mg} / \mathrm{kg}(\mathrm{p}<0.01)$.

On comparing FC concentrations in different grades of HE according to West-Haven criteria, fecal calprotectin levels were significantly higher in patients with grades $2-4$ in comparison to grades $0-1(p<0.01)$.

Table 3. The level of fecal calprotectin in HE group according to grades measured by West-Haven criteria.

\begin{tabular}{llllllll}
\hline \multirow{2}{*}{ Grade of $\mathbf{H E}$} & $\mathbf{0}$ & $\mathbf{1}$ & $\mathbf{2}$ & $\mathbf{3}$ & $\mathbf{4}$ & & \multirow{2}{*}{ P value } \\
& $\mathbf{N}=\mathbf{3}$ & $\mathbf{N}=\mathbf{9}$ & $\mathbf{N}=\mathbf{8}$ & $\mathbf{N}=\mathbf{7}$ & $\mathbf{N}=\mathbf{3}$ & \\
\hline Level of fecal calprotectin & $195 \pm 12$ & $239 \pm 19$ & $430 \pm 11$ & $468 \pm 14$ & $489 \pm 23$ & $<0.01$ \\
\hline
\end{tabular}

In the studied patients, there is a statistical significant inverse correlation between FC and serum albumin in uncomplicated cirrhotic patients. Also, there is a significant negative correlation between $\mathrm{FC}$ and serum $\mathrm{Na}^{+}$in $\mathrm{HE}$ patients (table 4).

Table 4. Correlation between fecal calprotectin and laboratory data among studied patients.

\begin{tabular}{|c|c|c|c|c|}
\hline \multirow{2}{*}{ Variables } & \multicolumn{2}{|c|}{ Uncomplicated Cirrhotics } & \multicolumn{2}{|l|}{ HE } \\
\hline & $\mathbf{R}$ & p value & $\mathbf{R}$ & p value \\
\hline Age & 0.11 & $>0.05$ & 0.15 & $>0.05$ \\
\hline HB & 0.13 & $>0.05$ & 0.16 & $>0.05$ \\
\hline Platelets & 0.02 & $>0.05$ & 0.04 & $>0.05$ \\
\hline WBCs & 0.03 & $>0.05$ & 0.08 & $>0.05$ \\
\hline PT & -0.17 & $>0.05$ & -0.11 & $>0.05$ \\
\hline INR & -0.15 & $>0.05$ & -0.19 & $>0.05$ \\
\hline Bilirubin & 0.1 & $>0.05$ & 0.14 & $>0.05$ \\
\hline ALT & 0.03 & $>0.05$ & 0.07 & $>0.05$ \\
\hline AST & 0.07 & $>0.05$ & 0.01 & $>0.05$ \\
\hline Albumin & -0.46 & $<0.05$ & -0.16 & $>0.05$ \\
\hline $\mathrm{Na}^{+}$ & 0.19 & $>0.05$ & -0.39 & $<0.05$ \\
\hline $\mathrm{K}^{+}$ & 0.05 & $>0.05$ & 0.03 & $>0.05$ \\
\hline Random blood sugar & 0.1 & $>0.05$ & -0.15 & $>0.05$ \\
\hline Creatinine & 0.05 & $>0.05$ & -0.17 & $>0.05$ \\
\hline BUN & 0.12 & $>0.05$ & -0.22 & $>0.05$ \\
\hline
\end{tabular}

On constructing ROC curve, fecal calprotectin has a sensitivity of $90 \%$ and specificity of $60 \%$ in diagnosing $\mathrm{HE}$ with a PPV and a NPV of $67 \%$ and $94 \%$ respectively at cutoff value of $280 \mathrm{mg} / \mathrm{kg}$ with AUC of 0.72 .

After receiving HE treatment, fecal calprotectin at cut-off value $190 \mathrm{mg} / \mathrm{kg}$ has sensitivity of $95 \%$ and specificity of $43 \%$ with PPV and NPV of 50\% and $96 \%$ in predicting response to treatment with area under the curve (AUC) of 0.47 (table 5, figure 2,3). 
Table 5. Validity of calprotectin in diagnosis of HE and follow up response to treatment.

\begin{tabular}{lllllll}
\hline Variables & Best cut & AUC* & Sensitivity & Specificity & PPV ** $^{*}$ & NPV*** \\
\hline HE before treatment & 280 & 0.72 & $90 \%$ & $60 \%$ & $67 \%$ & $94 \%$ \\
HE after treatment & 190 & 0.47 & $95 \%$ & $43 \%$ & $50 \%$ & $96 \%$ \\
\hline
\end{tabular}

*AUC: Area under the Curve

**PPV: Positive predictive value

***NPV: Negative predictive value

\section{ROC Curve}

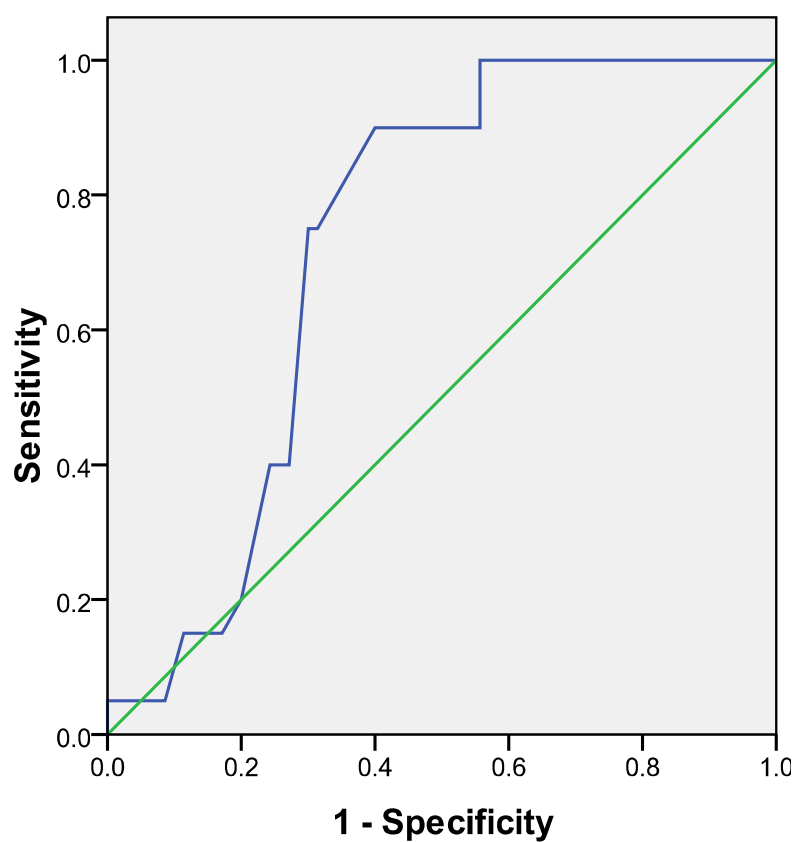

Figure 2. ROC curve for diagnostic performance of FC in HE patients.

\section{ROC Curve}

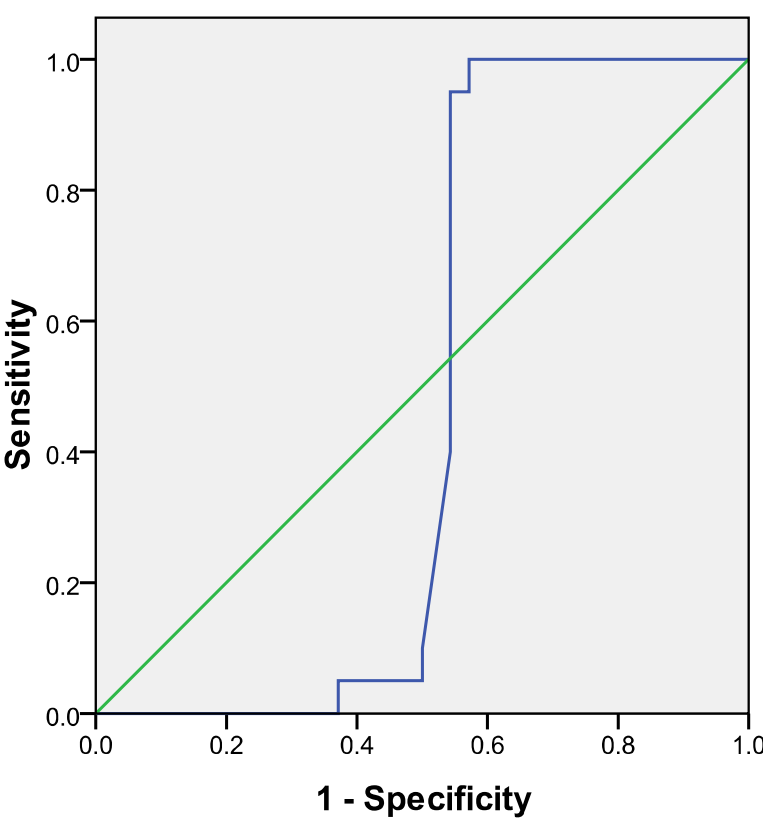

Figure 3. Roc curve for performance of $F C$ as a follow up marker in $H E$ patients.

\section{Discussion}

Fecal calprotectin is considered as a valid marker of intestinal inflammation because it is released during cell activation and death [3].

The high level of FC in patients with HE may be explained by small intestinal bacterial overgrowth. Gupta and colleagues studied the role of bacterial overgrowth of the small intestine among patients with minimal $\mathrm{HE}, 55.9 \%$ of patients with cirrhosis had minimal HE [7].

To address these issues, we examined whether fecal calprotectin represented a useful diagnostic tool for liver cirrhosis and hepatic encephalopathy. This may help assessing HE severity which may be subjective when using clinical criteria alone. We also examined whether, it is a useful marker for follow up response to treatment in HE patients.

In the present study, FC concentrations were significantly higher in cirrhotic patients $(76 \pm 15 \mathrm{mg} / \mathrm{kg})$ and $\mathrm{HE}$ patients $(364 \pm 83 \mathrm{mg} / \mathrm{kg}$ ) compared to control group $(31.2 \pm 9 \mathrm{mg} / \mathrm{kg})$. This was in agreement with Gundling et al. [8] who reported that the median FC were significantly higher in cirrhotic patients $(65.8 \mathrm{mg} / \mathrm{kg})$ compared to control group $(17.5 \mathrm{mg} / \mathrm{kg})$ $(\mathrm{p}<0.001)$. Also, Yagmur et al. [9] found significantly elevated FC in patients with advanced disease and a trend towards higher levels of FC in subjects with alcoholic cirrhosis.

It was supposed that elevated FC in cirrhotic patients may be caused by a regional intestinal inflammation [8]. Small intestinal bacterial overgrowth in patients with liver cirrhosis and intestinal barrier dysfunction in liver cirrhosis leads to infiltration of the intestinal mucosa with neutrophils and transmucosal passage of bacteria [10]. Gupta et al. [7], studied the role of small intestinal bacterial overgrowth in patients with minimal HE. He reported that among patients with minimal HE, $38.6 \%$ had small intestinal bacterial over growth. The prevalence of small intestinal bacterial over growth was higher in patients with Child- Pugh classes B and C (69.2\%) compared to those in class A (30.8\%).

The present study found that $\mathrm{FC}$ concentration was significantly higher in Child B $(116 \pm 12 \mathrm{mg} / \mathrm{kg})$ compared to Child A $(66 \pm 15 \mathrm{mg} / \mathrm{kg})$. This agreed with Salem et al. [11], who found increase FC with increased severity of liver disease, $52.19 \pm 16.99,182.5 \pm 74.81,311.47 \pm 90.92 \mathrm{mg} / \mathrm{kg}$ in Child A, B and C respectively.

In the present study, $\mathrm{FC}$ levels were significantly higher in patients with grades $2-4$ in comparison to grades $0-1(\mathrm{p}<0.01)$.

Similar result was reported by Gundling et al. [8] who elicited a correlation between elevated FC concentrations and HE grading as measured by West-Haven criteria and critical flicker frequency (both $\mathrm{P}<0.001$; sensitivity $=0.94$ and 0.93 , 
specificity $=0.95$ and 0.89 respectively). He concluded that FC may serve as a screening tool to identify cirrhotic patients with HE. Furthermore, assessment of FC may facilitate the grading of HE-severity which may be sometimes subjective when using only clinical criteria.

We found a significant inverse correlation between fecal calprotectin versus serum $(\mathrm{r}=-0.39, \mathrm{p}<0.05)$, this may be explained by the fact that serum sodium level is lower in advanced liver disease.

On constructing ROC curve, FC at cut-off value of 280 $\mathrm{mg} / \mathrm{kg}$ showed a sensitivity of $90 \%$ and specificity of $60 \%$ with PPV and NPV of $67 \%$ and $94 \%$ for diagnosing HE in cirrhotic patients with AUC of 0.72 .

A single study elicited that $\mathrm{FC}$ can differentiate HE patients with grading 0 and 1 from those with grading 2 and 3 according to the West-Haven criteria with a sensitivity of 0.94 and a specificity of 0.95 using an optimal cut-off value $164 \mathrm{mg} / \mathrm{kg}$ [8].

In present study, we followed up patients with $\mathrm{HE}$ after treatment, the level of Fecal calprotectin was significantly reduced $(\mathrm{p}<0.001)$ in HE group after receiving treatment, reaching to a level of $273 \pm 42.68 \mathrm{mg} / \mathrm{kg}$ versus $364 \pm 83.12$ $\mathrm{mg} / \mathrm{kg}$ before treatment.

We found that $\mathrm{FC}$ at cut-off value $190 \mathrm{mg} / \mathrm{kg}$ has a high sensitivity (95\%) in predicting response to treatment but with a low specificity (43\%), PPV and NPV of $50 \%$ and $96 \%$ respectively and area under ROC curve of 0.47 . This reduction of fecal calprotectin after treatment may indicate that it might be of benefit in association with clinical signs for follow up HE patients during treatment.

\section{Conclusion}

Fecal calprotectin was significantly elevated in hepatic encephalopathy patients compared to both cirrhotic patients and healthy control, reaching the highest value in the high grade HE group. FC can be used as a diagnostic marker for hepatic encephalopathy and may be of help in assessing severity of the disease. Reduction of Fecal calprotectin in patients with hepatic encephalopathy after treatment could consider fecal calprotectin as a follow up marker in association with clinical signs in patients with hepatic encephalopathy.

\section{References}

[1] K. Gyr, R. Meier, "Flumazenil in the treatment of portal systemic encephalopathy-an overview,". Intens. Care. Med., vol. 17, pp. S39-S42, 1991.
[2] R. D' Inca, E. Dal Pont, V. Di Leo, L. Benazzato, M. Martinato, F. Lambogia, L. Oliva, G. C. Sturniolo, "Can calprotectin predict relapse risk in inflammatory bowel disease?" Am. J. Gastroenterol., vol. 103, pp. 2007-2014, 2012.

[3] P. Ferenci, A. Lockwood, K. Mullen, R. Tarter, K. Weissenborn, A. T. Blei, "Hepatic encephalopathy-definition, nomenclature, diagnosis, and quantification: final report of the working party at the 11th World Congress of Gastroenterology, Vienna, 1998". Hepatology, vol. 35, pp. 716-721, 2012.

[4] A. Mas, J. Rodes, L. Sunyer, L. Rodrigo, R. Planas, V. Vargas, et al., "Comparison of rifaximin and lactitol in the treatment of acute hepatic encephalopathy: results of a randomized, double-blind, double-dummy, controlled clinical trial." J. Hepatol., vol. 38 (1): pp. 51-8, 2013.

[5] S. Joshi, S. J. Lewis, S. Creanor, R. M. Ayling, "Age-related fecal calprotectin, lactoferrin and tumour M2-PK concentrations in healthy volunteers". Annals of Clinical Biochemistry, Vol. 47 (3): pp. 259-263, 2009.

[6] W. J. Cash, P. McConville, E. McDermott, P. A. McCormick, M. E. Callender, N. I. McDougall. "Current concepts in the assessment and treatment of hepatic encephalopathy". Q. J. M., vol. 103 (1), pp. 9-16, 2013.

[7] A. Gupta, R. K. Dhiman, S. Kumari, S. Rana, R. Agrawal, A. Duseja, Y. Chawla. "Role of small intestinal bacterial overgrowth and delayed gastrointestinal transit time in cirrhotic patients with minimal hepatic encephalopathy". J. Hepatol. Vol. 53, pp. 849-55, 2015.

[8] F. Gundling, F. Schmidtler, A. Hapfelmeier, B. Schulte, T. Schmidt, C. Pehl, W. Schepp, H. Seidl. "Fecal calprotectin is a useful screening parameter for hepatic encephalopathy and spontaneous bacterial peritonitis in cirrhosis". Liver international, vol. 31 (9), pp. 1406-1415, 2011.

[9] E. Yagmur, B. Schnyder, D. Scholten, R. Schirin-Sokhan, A. Koch, R. Winograd, A. M. Gressner, C. Trautwein, H. E., Wasmuth "Elevated concentration of fecal calprotectin in patients with liver cirrhosis". Dtsch. Med-Wochenschr., vol. 131 (36), pp. 1930-4, 2015.

[10] V. A. Gerova, V. N. Nakov, S. G. Stoynov, R. V. Nakov, "Prevalence of small intestinal bacterial overgrowth in patients with liver cirrhosis." Journal of Gastroenterology and Hepatology Research, vol. 212 (8), pp. 740-743, 2015.

[11] H. Salem, M. Mansour, A. Elsaady, M. Mohsen, K. Mansour, "Relation between fecal calprotectin concentration and severity of Hepatitis $\mathrm{C}$ related chronic liver disease." Int. J. Adv. Res. Biol. Sci., vol. 2 (7), pp. 115-125, 2015. 